\title{
Dexamethasone and outcome of meconium aspiration syndrome: Vijayapur, Karnataka experience
}

\author{
*Mallanagouda M Patil ${ }^{1}$, Bhavana Bhushan Lakhkar ${ }^{2}$, Shankargouda V Patil ${ }^{3}$
}

Sri Lanka Journal of Child Health, 2018; 47(1): 21-26

Introduction: Meconium aspiration is an important cause of respiratory distress and mortality in the newborn. Steroid therapy is one of the strategies in management due to its anti-inflammatory action. So far enough evidence is not available in its favour.

Objectives: To assess the utility of intravenous (IV) dexamethasone in meconium aspiration syndrome (MAS) and to study any immediate adverse outcome and/or increase in sepsis in newborns receiving dexamethasone.

Method: A prospective, interventional study was carried out in the neonatal intensive care unit (NICU) of a tertiary hospital. Newborns were enrolled using selection criteria and were randomized into an intervention group and a control group. After collecting baseline data, the intervention group was administered $0.5 \mathrm{mg} / \mathrm{kg}$ IV dexamethasone in two divided doses starting from the age of 24 to 36 hours. A total of 6 doses were administered. Outcome measures noted were: period of oxygen dependency, duration of NICU stay, initiation of oral feeds and development of sepsis in both intervention group and control group. Any adverse effects with dexamethasone therapy was noted in babies randomized as intervention group. Investigations and management were carried out as per unit protocol. SPSS Software version 23 was used for statistical purposes. A $p$ value of $<0.05$ was considered significant.

Results: Both intervention group and control group were comparable in subject characteristics. Duration of NICU stay less than 6 days and oxygen requirement less than 50 hours were significantly more in the intervention group. There was no

\footnotetext{
${ }_{1}^{1}$ Associate Professor Pediatrics, ${ }^{2}$ Professor Pediatrics, ${ }^{3}$ Professor and Head of Department, Pediatrics, Shri BM Patil Medical College, BLDE University, Vijayapur, Karnataka, India

*Correspondence: mmp076@gmail.com

(Received on 02 April 2017: Accepted after revision on 19 May 2017)

The authors declare that there are no conflicts of interest

Personal funding was used for the project.

Open Access Article published under the Creative
}

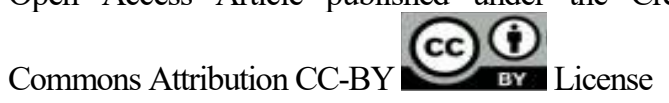

increase in sepsis or any other adverse effect noticed in the intervention group. Initiation of feeding was comparable in both groups. Mechanical ventilation was needed in 4 in the intervention group and there was one death in the control group.

Conclusions: In Shri B.M Patil Medical College, Hospital and Research Centre, Vijayapur Karnataka, IV dexamethasone was found to be useful in MAS in reduction of NICU stay and oxygen requirement with no increase in sepsis or any other adverse effects.

DOI: http://dx.doi.org/10.4038/sljch.v47i1.8425

(Key words: Meconium aspiration, steroid therapy, respiratory distress)

\section{Introduction}

Meconium aspiration syndrome (MAS) occurs in about $10 \%$ of babies delivered through meconium stained amniotic fluid (MSAF) ${ }^{1}$. It is a major cause of neonatal respiratory distress ${ }^{2}$. Meconium aspiration leads to pulmonary macrophage activation and polymorphonuclear leucocytic infiltration of the lungs ${ }^{3}$. The synthetic glucocorticoid dexamethasone has metabolic and anti-inflammatory effects. Its anti-inflammatory action results from inhibition of transcription factors and inhibition of the expression of proinflammatory cytokines, enzymes and other biologically active substances ${ }^{2,4}$. Dexamethasone, by direct modulation of pulmonary vasomotor tone, diminishes pulmonary vasoconstriction which is responsible for pulmonary hypertension and inhibits fibrogenesis ${ }^{5}$. Different studies which used steroids in MAS have shown contradictory results ${ }^{5-8}$. The present study is intended to assess the effect of intravenous (IV) dexamethasone administration on the outcome of MAS with definite outcome measures.

\section{Objectives}

- To assess the utility of IV dexamethasone in MAS.

- To study any immediate adverse outcome and/or increase in sepsis in newborns receiving dexamethasone.

Method

Study design: Prospective interventional study. 
Inclusion criteria: Babies who are late preterm (3436 weeks), term ( $\geq 37$ weeks) or post-term with MSAF and respiratory distress persisting at 24 to 36 hours.

Exclusion criteria: Babies with significant congenital malformations, denial of consent, suspected sepsis (clinical signs e.g. poor feeding, lethargy, sclerema, delayed capillary filling time $>3 \mathrm{sec}$ ) or had positive sepsis screen or proved sepsis (positive blood culture) at the time of admission.

The study was approved by institutional ethical committee.

The study was conducted in the neonatal intensive care unit (NICU) of Shri B.M. Patil Medical College, Hospital and Research Centre, Vijayapur Karnataka over a period of one and half years. All the neonates fulfilling inclusion criteria with no exclusion criteria, were recruited and were randomized as intervention group and control group. Demographic and clinical details of baby, detailed maternal history like age, parity, events during pregnancy, details of labour, mode of delivery, investigations, monitoring details and outcome measures were noted in a pretested prevalidated proforma and babies were followed up until discharge or death. Investigations such as sepsis screen (total count, differential count, micro erythrocyte sedimentation rate, band neutrophil ratio, C-reactive protein) X-ray chest, arterial blood gas $(\mathrm{ABG})$ and blood culture were carried out in all patients. Rest of the investigations were carried out as per unit protocol. Monitoring was carried out using Downes score and complete clinical examination including capillary refill time and pulse oximetry.

Both intervention group and control group received treatment as per NICU protocol for management of MAS. Babies randomized as intervention group received additional IV dexamethasone $0.5 \mathrm{mg} / \mathrm{kg}$ twice a day in divided doses. Starting from 24 to 36 hours, a total of 6 doses were administered. Outcome measures noted were: period of oxygen dependency, duration of NICU stay, initiation of oral feeds and development of sepsis in intervention group and control group. Any adverse effects with dexamethasone therapy were noted.

SPSS 23.0 version software was used for statistical calculations. Chi-square $(\chi 2)$ / Freeman-Halton Fisher exact test was employed to determine the significance of differences between the groups for categorical data. The difference of the means of variables was tested by unpaired t-test. If the $p$ value was $<0.05$, then the result was considered to be significant.

\section{Results}

A total of 70 babies was recruited for the study of which 34 were in the intervention group and 36 in the control group. Subject characteristics are presented in table 1 and are comparable. Table 2 shows comparison of outcome measures.

Table 1: Baseline characteristics of intervention group and control group

\begin{tabular}{|l|c|c|c|}
\hline \multicolumn{1}{|c|}{ Parameter } & Intervention group (n=34) & Control group (n=36) & $\boldsymbol{p}$ value \\
\hline Age of mothers (years) [mean \pm SD] & $25.3 \pm 2.3$ & $24.9 \pm 2.0$ & $>0.05$ \\
\hline Antenatal registration [No. (\%)] & $26(76.5)$ & $27(75.0)$ & $>0.05$ \\
\hline Primigravida : multi gravida & $22: 12$ & $20: 16$ & $>0.05$ \\
\hline Mode of delivery & $26(76.5)$ & $26(72.2)$ & $>0.05$ \\
Normal vaginal delivery [No. (\%)] & $08(23.5)$ & $10(27.8)$ & \\
Caesarean section [No. (\%)] & $38.9 \pm 1.2$ & $38.8 \pm 1.1$ & $>0.05$ \\
\hline Gestational age (weeks) [mean \pm SD] & $2.7 \pm 0.3$ & $2.7 \pm 0.4$ & $>0.05$ \\
\hline Birth weight $(\mathrm{kg})$ & $20: 14$ & $21: 15$ & \\
\hline Male : Female & & & \\
\hline Apgar score [mean \pm SD] & $6.5 \pm 1.0$ & $8.3 \pm 1.3$ & $>0.05$ \\
At birth & $8.5 \pm 1.0$ & $8.7 \pm 0.5$ & \\
At 1 minute & $8.5 \pm 0.5$ & $3.5 \pm 1.5$ & $>0.05$ \\
At 5 minutes & $3.6 \pm 1.6$ & & \\
\hline Downes score at admission [mean \pm SD] & & & \\
\hline
\end{tabular}


Table 2: Outcome measures in intervention group and control group

\begin{tabular}{|l|c|c|c|}
\hline \multicolumn{1}{|c|}{ Outcome measure } & $\begin{array}{c}\text { With dexamethasone (n=34) } \\
\text { No. (\%) }\end{array}$ & $\begin{array}{c}\text { Without dexamethasone (n=36) } \\
\text { No. (\%) }\end{array}$ & $\boldsymbol{p}$ \\
\hline $\begin{array}{l}\text { Duration of PICU stay } \\
\text { Less than 6 days } \\
\text { 6 or more days }\end{array}$ & $31(91.2)$ & $29(80.6)$ & $<07(19.4)$ \\
\hline $\begin{array}{l}\text { Duration of oxygen } \\
\text { requirement }\end{array}$ & $32(08.8)$ & $31(86.1)$ & $<0.05$ \\
$\begin{array}{l}\text { Less than 50 hours } \\
\text { 50 or more hours }\end{array}$ & $02(05.9)$ & $05(13.9)$ & $<0.01$ \\
\hline $\begin{array}{l}\text { Breastfeeds (expressed } \text { or } \\
\text { direct) }\end{array}$ & $16(47.0)$ & $18(50.0)$ & $<0.01$ \\
$\begin{array}{l}\text { Less than 48 hours } \\
\text { 48-96 hours }\end{array}$ & $13(38.0)$ & $12(33.0)$ & $>0.05$ \\
More than 96 hours & $05(12.0)$ & $06(17.0)^{*}$ & $>0.05$ \\
\hline Need for mechanical ventilation & $04(11.7)$ & $01(02.7)$ & $<0.05$ \\
\hline
\end{tabular}

* One baby expired

Duration of NICU stay and oxygen requirement were significantly less in the dexamethasone group, though significantly more children needed ventilation among the intervention group. Among 5 ventilated children, 3 needed ventilation for more than 96 hours indicating the presence of severe MAS. Feeding initiation was similar in the two groups. Radiological abnormalities (hyperinflation /infiltrations) were seen in all patients and $75 \%$ of patients had infiltrations. Sepsis parameters especially total counts, $\mathrm{C}$ reactive protein (CRP) and band neutrophil ratio was positive in only 3 patients among the intervention group and 5 among the control group. Other associated problems were hyperbilirubinaemia in 5 in the intervention group and 7 in the control group, hypoxic ischaemic encephalopathy (HIE) stage I in 2 in the intervention group and 3 in the control group and HIE stage II in 2 in the intervention group and 1 in the control group. Blood cultures were negative in all patients. There was no air leak and only one death (control group). Other drugs used concomitantly were adrenaline or salbutamol nebulisation (4 in the intervention group, 2 in the control group), Surfactant was given in only one patient from the control group and pulmonary vasodilators in 3 in the intervention group and 4 in the control group.

\section{Discussion}

Meconium aspiration is one of the common causes for NICU admission. Management is difficult in severe cases with a high mortality. Meconium aspiration is also thought to be a factor contributing to late effects like hyperactive airway disease, recurrent wheeze and neurodevelopmental problems. Constant efforts to improve the strategy for management are going on. One of the strategies is to use steroids due to their anti-inflammatory action which is one of the major factors in the complex pathophysiology of MAS. Convincing evidence in favour of steroids is lacking and more research in the field might help in resolving some of the issues. Present study analyses the short term advantages with steroids.

We used dexamethasone intravenously for its strong anti-inflammatory activity (around 30 times more than hydrocortisone). A total of 6 doses were given at 12 hourly intervals. Dexamethasone in meconium aspiration was first found to be successful in the year $1999^{8}$. Later it was tried in many studies ${ }^{9-12}$. Most studies used the same dose as ours $(0.5 \mathrm{mg} / \mathrm{kg})$, but with varied frequency and duration. Based upon the half-life of dexamethasone in the newborn (150-300 $\mathrm{min}$ ) most studies have used repetitive doses ${ }^{13}$ with duration ranging from 5 to 7 days. Costa et al used tapering doses over 9 days ${ }^{14}$. Mokra et $a l^{10,11}$ found repetitive doses of dexamethasone efficacious as compared to single dose in rabbits but also noticed a variable effect on the heart rate. In the present study we found steroids were useful even when given for 48 hours and hence it is better to choose this duration so that other side effects can be avoided. We did not notice any change in vital parameters after steroids.

In the present study we waited for 24 hours before administering dexamethasone so that steroids can be avoided in cases of transient tachypnoea. In animal models it was noticed that if dexamethasone was given one hour prior to meconium instillation, effects were specific on vascular resistance, oedema and neutrophil counts in lung fluid, leading to better oxygenation and reduction in pulmonary hypertension. Late administration of dexamethasone had only nonspecific actions $\mathrm{s}^{9,10}$. This difference between early and late steroid administration was also noticed by Soukka et al ${ }^{14}$ who used methylprednisolone in piglets. Early administration of dexamethasone can be tried in newborn with MAS with severe distress and obvious radiological 
findings. Premedication with steroids before delivery is also suggested though so far it has not been tried ${ }^{4}$. In our subjects among the intervention group, 4 neonates needed ventilatory support $(\mathrm{p}$ $<0.05$ ). Early administration of dexamethasone might have avoided this.

Other steroid molecules used in patients with MAS are hydrocortisone, prednisolone, methyl prednisolone $^{14}$ and budesonide. Hydrocortisone has poor anti-inflammatory activity and when tried in animal model, increased mortality was noted without any significant benefit. Severe pulmonary oedema was noticed in these animals, perhaps due to the mineralocorticoid action of hydrocortisone ${ }^{15}$. Kirime $\mathrm{E}$ et $a l^{16}$ revealed high dose IV methyl prednisolone produced more clinical benefit when compared to the standard dose but with increased risk of oxidative stress in puppies. The main advantage with budesonide was the route of administration. It was administered through intratracheal route in rabbits and effects were much better and it alleviated side effects noticed by systemic dexamethasone, like heart rate variability with reduction of oxidation injury to lungs ${ }^{4,8}$. Basu et al in their trial on newborns, used nebulized budesonide and compared it with systemic methylprednisolone and control group (no steroid group) of newborns and found steroids useful with no toxic effects irrespective of route of administration $^{2}$. Inhalational steroids, though easy to administer only $20 \%$ reaches the lungs, which may be a reason it was not found superior to systemic steroids.

Intra-tracheal administration of budesonide was found to yield better results. Budesonide used with high frequency jet ventilation was found to be better with minimal extra-pulmonary losses ${ }^{4}$. Tripathi et $a l^{1,5}$ reported better oxygenation and reduced hospital stay with intra-tracheal budesonide. They also noticed decrease in level of inflammatory markers (TNFà) and no increase in sepsis, which is a potential threat with systemic steroids.

Addition of other drugs like surfactant to steroids has been tried and has shown better results ${ }^{15,18}$. The property of surfactant remained the same but still the advantage of steroids could be noticed. Premedication with methyl-prednisolone followed by surfactant lavage was found more useful ${ }^{19}$. Intratracheal route, though found to be effective, is more invasive and can be used in babies in need of intubation or intubation during instillation followed by extubation also can be tried. Other drugs used were theophylline ${ }^{20}$ and $\mathrm{N}$ acetylcysteine ${ }^{21}$ and $\beta 2$ agonist $^{22}$. They all were found to improve lung functions with no adverse effects. We could not study the effect of these drugs used as they were used in very few cases.

Many authors have compared radiological clearing in cases with steroids and controls. As per NICU protocol chest X-ray was not repeated (to keep radiation exposure minimum) unless clinically lung deterioration was noticed hence this parameter could not be compared ${ }^{2}$. Though systemic steroids were used it did not lead to increase in sepsis may be because all the newborns with meconium aspiration were on antibiotics from beginning as per our NICU protocol. Though local steroids may be more justified, looking at the toxicity potential of steroids, we have not used them. Study of long term effect especially on neurodevelopment was beyond the scope of study.

\section{Conclusions}

In Shri B.M Patil Medical College, Hospital and Research Centre, Vijayapur Karnataka, IV dexamethasone was found to be useful in MAS in reduction of NICU stay and oxygen requirement with no increase in sepsis or any other adverse effects.

\section{References}

1. Tripathi S, Saili A, Dutta R. Inflammatory markers in meconium induced lung injury in neonates and the effect of steroids on their levels; a randomized controlled trial. Indian Journal of Medical Microbiology 2007; 25:103-7.

https://doi.org/10.4103/0255-0857.32714

PMid: 17582178

2. Basu S, Kumar A, Bhatia BD, Satya K, Singh TB. Role of steroids on the clinical course and outcome of meconium aspiration syndrome - a randomized controlled trial. Journal of Tropical Pediatrics 2007; 53(5):331-7. https://doi.org/10.1093/tropej/fmm035 PMid: 17535827

3. Kojima T, Hattori K, Fujiwara T, SasaiTakedatsu M, Kobayashi Y. Meconiuminduced lung injury mediated by activation of alveolar macrophages. Life Sciences 1994; 54(21):1559-62.

https://doi.org/10.1016/00243205(94)9002 6-4

4. Mokra D, Mokry J. Glucocorticoids in the treatment of neonatal meconium aspiration syndrome. European Journal of Pediatrics 2011; 170(12):1495-505. 
https://doi.org/10.1007/s00431-011-1453-2

PMid: 21465122 PMCid: PMC3221844

5. Tripathi S, Saili A. The effect of steroids on the clinical course and outcome of neonates with meconium aspiration syndrome. Journal of Tropical Pediatrics 2007; 53(1):8-12.

https://doi.org/10.1093/tropej/fml018

PMid: 16705003

6. da Costa DE, Nair AK, Pai MG, Al Khusaiby SM. Steroids in full term infants with respiratory failure and pulmonary hypertension due to meconium aspiration syndrome. European Journal of Pediatrics 2001; 160(3):150-3.

https://doi.org/10.1007/s004310000678

PMid: 11277374

7. Chettri S, Bhat BV, Adhisivam B. Current concepts in the management of meconium aspiration syndrome. Indian Journal of Pediatrics 2016; 83(10):1125-30.

https://doi.org/10.1007/s12098-016-2128-9

PMid: 27206687

8. Wu JM, Yeh TF, Wang JY, Wang JN, Lin YJ, Hsieh WS, Lin $\mathrm{CH}$. The role of pulmonary inflammation in the development of pulmonary hypertension in newborn with meconium aspiration syndrome (MAS). Pediatric Pulmonology 1999; 27(S18):205-8.

https://doi.org/10.1002/(SICI)10990496(19 99) $27: 18+<205:: A I D-P P U L 66>3.3 . C O ; 2-$ $\mathrm{S}$

9. Holopainen R, Laine J, Halkola L, Aho H, Kääpä P. Dexamethasone treatment attenuates pulmonary injury in piglet meconium aspiration. Pediatric Research 2001; 49(2):162-8.

https://doi.org/10.1203/000064502001020 00-00006

PMid: 11158508

10. Mokra D, Mokry J, Drgova A, Bulikova J, Petraskova M, Calkovska A. Single-dose versus two-dose dexamethasone effects on lung inflammation and airway reactivity in meconium-instilled rabbits. Journal of Physiology and Pharmacology 2007; 58(5):379-87.

PMid: 18204150

11. Mokra D, Calkovska A, Tonhajzerova I, Petraskova M, Bulikova J, Redfors B. Dexamethasone treatment improved lung functions in meconium-instilled rabbits, but influenced cardiovascular variables. Bratislavske Lekarske Listy 2008; 109(3): 95.

PMid: 18517130

12. Mokra D, Tonhajzerova I, Mokry J, Drgova A, Petraskova M, Calkovska A, Javorka K. Rapid cardiovascular effects of dexamethasone in rabbits with meconiuminduced acute lung injury. Canadian Journal of Physiology and Pharmacology 2008; 86(11):804-14. https://doi.org/10.1139/Y08-086 PMid: 19011676

13. Miller WL, Achermann JC, Flück CE. The adrenal cortex and its disorders. In: Sperling MA, editors. Pediatric endocrinology. $3^{\text {rd }}$ ed. Philadelphia: Saunders Elsevier; 2008. p 444-511. https://doi.org/10.1016/B978-1416040903.50017-X

14. Soukka H, Halkola L, Aho H, Rautanen M, Kero P, Kääpä P. Methylprednisolone attenuates the pulmonary hypertensive response in porcine meconium aspiration. Pediatric Research 1997; 42(2): 145-50. https://doi.org/10.1203/000064501997080 00-00003

PMid: 9262214

15. Frantz ID, San Wang N, Thach BT. Experimental meconium aspiration: effects of glucocorticoid treatment. Journal of Pediatrics 1975; 86(3):438-41. https://doi.org/10.1016/S00223476(75)809 81-4

16. Kirimi E, Tuncer O, Kösem M, Ceylan E, Tas A, Tasal I, Balahoroğlu R, Caksen H. The effects of prednisolone and serum malondialdehyde levels in puppies with experimentally induced meconium aspiration syndrome. Journal of International Medical Research 2003; 31(2):113-22.

https://doi.org/10.1177/147323000303100 207

PMid: 12760314

17. Yeh TF, Lin HC, Chang CH, Wu TS, Su BH, Li TC, Pyati S, Tsai CH. Early intratracheal instillation of budesonide using surfactant as a vehicle to prevent chronic lung disease in preterm infants: a pilot study. Pediatrics 2008; 121(5):e13108. 
https://doi.org/10.1542/peds.2007-1973

PMid: 18426851

18. Nimmo AJ, Carstairs JR, Patole SK, Whitehall J, Davidson K, Vink R. Intratracheal administration of glucocorticoids using surfactant as a vehicle. Clinical and Experimental Pharmacology and Physiology 2002; 29(8): 661-5.

https://doi.org/10.1046/j.14401681.2002.0

3712.x

PMid: 12099996

19. Salvia-Roigés MD, Carbonell-Estrany X, Figueras-Aloy J, Rodríguez-Miguélez JM. Efficacy of three treatment schedules in severe meconium aspiration syndrome. Acta Paediatrica 2004; 93(1):60-5. https://doi.org/10.1111/j.16512227.2004.tb 00675. $\mathrm{x}$

PMid: 14989441

20. Ito K, Lim S, Caramori G, Cosio B, Chung KF, Adcock IM, Barnes PJ. A molecular mechanism of action of theophylline: induction of histone deacetylase activity to decrease inflammatory gene expression. Proceedings of the National Academy of Sciences 2002; 99(13):8921-6.

https://doi.org/10.1073/pnas.132556899

PMid: 12070353 PMCid: PMC124399

21. Jansson AH, Eriksson C, Wang X. Effects of budesonide and $\mathrm{N}$-acetylcysteine on acute lung hyperinflation, inflammation and injury in rats. Vascular Pharmacology 2005; 43(2):101-11.

https://doi.org/10.1016/j.vph.2005.03.006

PMid: 15967733

22. Wang J, Zhang L, Walther SM. Administration of aerosolized terbutaline and budesonide reduces chlorine gasinduced acute lung injury. Journal of Trauma and Acute Care Surgery 2004; 56(4): 850-62.

https://doi.org/10.1097/01.TA.0000078689 $.45384 .8 \mathrm{~B}$ 